\title{
Medical Direct Cost of Hospital Admission for Cerebrovascular Accident on Medical Recovery at the Sylvanus Olympio Teaching Hospital of Lomé
}

\author{
Abago Balaka1, Toyi Tchamdja2 ${ }^{2}$, Kodjo Agbéko Djagadou', Hamadi Assane ${ }^{3}$, \\ Komi Dzidzonu Némi ${ }^{1}$, Mohaman Awalou Djibril ${ }^{1}$
}

${ }^{1}$ Department of Internal Medicine, Faculty of Health Sciences, University of Lomé, Lomé, Togo

${ }^{2}$ Department of Internal Medicine, Faculty of Health Sciences, University of Kara, Kara, Togo

${ }^{3}$ Department of Physiology, Faculty of Health Sciences, University of Lomé, Lomé, Togo

Email: *ttpault234@gmail.com

How to cite this paper: Balaka, A., Tchamdja, T., Djagadou, K.A., Assane, H., Némi, K.D. and Djibril, M.A. (2017) Medical Direct Cost of Hospital Admission for Cerebrovascular Accident on Medical Recovery at the Sylvanus Olympio Teaching Hospital of Lomé. Open Journal of Internal Medicine, 7, 165-171.

https://doi.org/10.4236/ojim.2017.74018

Received: October 3, 2017

Accepted: December 19, 2017

Published: December 22, 2017

Copyright () 2017 by authors and Scientific Research Publishing Inc. This work is licensed under the Creative Commons Attribution International License (CC BY 4.0).

http://creativecommons.org/licenses/by/4.0/ (c) (i) Open Access

\begin{abstract}
Objectives: Appreciate the Medical direct cost for cerebrovascular accident on medical recovery at the Sylvanus Olympio Teaching Hospital of Lomé. Patients and method: This was a prospective and cross study that took place from $01^{\text {st }}$ October 2015 to 31 st July 2016 in the medical recovery Unit of Sylvanus Olympio Teaching Hospital of Lomé. Results: Of the 91 stroke patients surveyed, the average age was 55.1 years; the sex-ratio (Men/women) was 1.3 and only $8.8 \%$ of patients had benefited from INAM (National Institute of Health Insurance) granting of benefits. The proportion of ICVA was $73.6 \%$ compared to $26.4 \%$ for the MCVA. The average overall cost of granting benefits of a CVA patient was 312,245 FCFA for an average stay of 18.6 days. This cost was 399.115 FCFA in MCVA for an average stay of 19.0 days against 281.130 FCFA in ICVA for an average stay of 16.1 days. Conclusion: CVAs on the one hand inflict losses of national productivity by its handicap, and a heavy economic burden for both patients and their families on the other hand, by its high cost of granting of benefits; Hence there is the need for assistance of all kinds by national and international health actors.
\end{abstract}

\section{Keywords}

Cerebrovascular Accidents, Cost, Granting of Benefits, Sylvanus Olympio Teaching Hospital of Lomé, Togo

\section{Introduction}

The World Health Organization (WHO) defines cerebrovascular accidents CVA 
as "the rapid development of clinical signs localized or global of cerebral dysfunction with symptoms for more than 24 hours, leading to death without further apparent cause but of a vascular origin" [1]. CVA can be hemorrhagic (HCVA) or ischemic (ICVA). Incidence and mortality related to CVA are increasing in developing countries due to the emergence of non-transmittable diseases as well as their associated risk factors.

As examples: High blood pressure (hypertension), diabetes, dyslipidemia, obesity, lifestyle changes (sedentary, alcoholism, smoking) and demographic growth with increased life expectancy [2]. CVA burden is not only limited to the loss of autonomy that it immediately causes but also to the cost of hospital care emergency in order to avoid the death of the patient.

These costs may vary from one patient to another and from one country to another. Thus, the average direct cost of admission in neurology of CVA patient in Benin [3] was estimated at 774.9 USD in 2013 compared to 633.6 USD in Togo [4] in 2004. These studies have been carried out in neurology units or many other patients with CVA are also admitted in other units as the medical recovery unit. In this unit, there is a lack of data related to the cost of admission. This is why this current study has been carried out in order to appreciate the direct medical cost of admission for CVA in medical recovery of Sylvanus Olympio Teaching Hospital of Lomé.

\section{Patient and Method}

This is a sectional study that covered a period of 10 months from October 4, 2015 to July 31, 2016. It took place in the medical recovery unit of the Sylvanus Olympio Teaching Hospital of Lomé. Patients of both gender of 18 years and over were admitted of CVA. There isn't any estimation of size of the sample. All the patients admitted and having cerebrovascular accident were included. All the patients who haven't accepted to participate at the study were excluded of study. The CVA diagnosis was kept on the basis of clinical symptomatology associated with an evocative scannographic image.

Data collection form was our tool. Collection technique consisted of direct interviews with the patients or with those who accompanied them in case they were in state of unconsciousness or incapacity. However, patient records were also used to complete missing information.

Questions were asked by medical psychologist involved in psychological grant of benefits to patients with CVA. Needed information were: socio-demographic data (age, gender, occupation, residence, marital status, monthly income, health insurance card), type of admission, type of CVA (ischemic or hemorrhagic), Duration of hospital admission (in days), means of transportation (taxi, ambulance, personal car), pharmacy (medicines and pharmaceutical consumables), rehabilitation (physiotherapy, speech therapy); monetary data (total, average, and direct costs). They were direct and non-medical costs.

Medical costs consisted of direct expenses related to medical services (consultation, hospital admission, pharmacy, para-clinical analysis, medical services). 
Non-medical expenditures were concerned with to all secondary expenses resulted from grant of benefits (transport, food). The unit of cost value was CFA (money used in Togo) currency, (one US dollar is corresponding to $500 \mathrm{CFA}$ ).

Data were analysed using epiinfo and stata.

All the patients have been informed of the aims of study and only those who have accepted have participate on study.

\section{Results}

\subsection{Epidemiological Data}

During the period of study, the medical recovery unit of the Sylvanus Olympio Teaching Hospital, had admitted 389 patients including 112 CVA patients. The frequency of CVA was $28.8 \%$. Of them, only 91 patients met our inclusion criteria. The average age of CVA was $55.1 \pm 11.8$ years old with extremes of 33 to 78 years. Depending on the type, the average age is $58.5 \pm 10.9$ years with extremes ranging from 35 to 78 years for ICVA and $45.6 \pm 8.3$ years with extremes of 33 to 59 years for HCVA. One noted male predominance with a sex-ratio of 1,3 . As for instruction level, (37.3\%) were not included. Patients with an income between 70 and 200 USD were the most represented at a rate of $52.7 \%$ followed by those with a monthly income of less than 70 USD (34.1\%) and those with an income of more than 200 USD. Regarding the socio-professional category, traders predominated at $35.2 \%$ (Table 1 ).

\subsection{Clinical Data}

Patients suffered more with CVA (73.6\%). The average duration of stay (DMS/ADS) of patients in our study was $18.6 \pm 7.3$ days with a minimum of 03 days and a maximum of 36 days and $29.5 \%$ had a duration stay of 5 to 10 Days (Figure 1). Depending on the type, DMS was $16.1 \pm 5.9$ for ICVA compared to $19.0 \pm 11.4$ days for HCVA.

Table 1. Patients distribution by socio-professional group.

\begin{tabular}{ccc}
\hline & Number & Percentage(\%) \\
\hline Civil servant & 7 & 7.7 \\
Private profession & 16 & 17.6 \\
Housewife & 10 & 10.9 \\
Trader & 32 & 35.2 \\
Retired & 7 & 7.7 \\
Unemployed & 3 & 3.3 \\
Crafsman & 15 & 16.5 \\
Student & 1 & 1.1 \\
Total & 91 & 100.0 \\
\hline
\end{tabular}




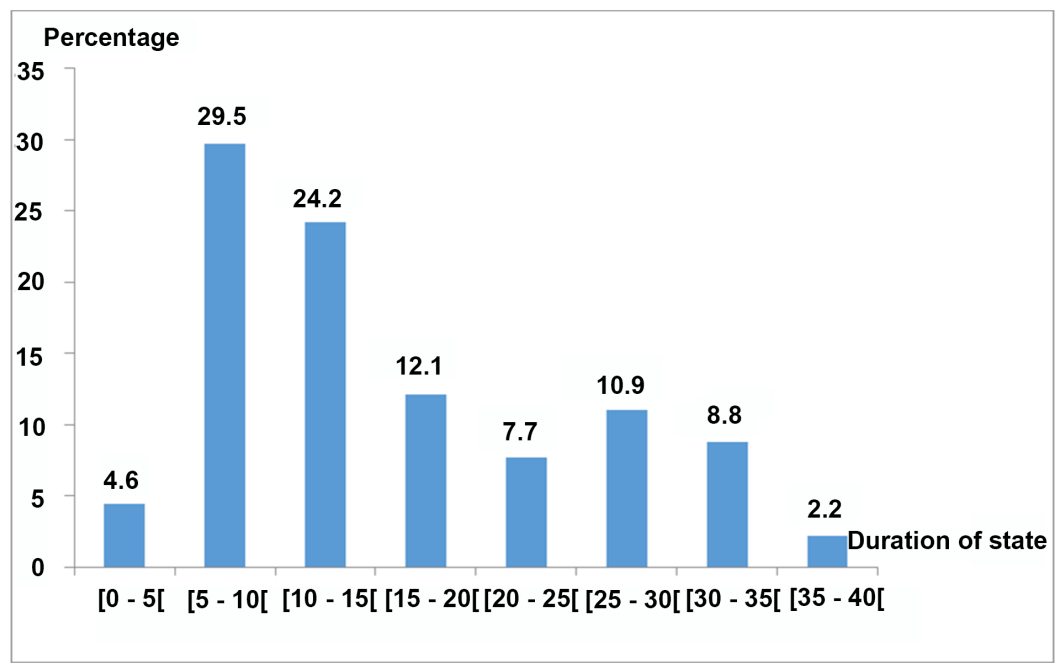

Figure 1. Patient distribution in respect of duration of admission.

\subsection{Economic Data}

The direct average cost of our study was $624.49 \pm 197.43$ with a minimum of 236.44 USD and a maximum at 1153.74 USD. In terms of cost items, drug costs were the largest with an average cost of $242.31 \pm 78.91$ USD. The average overall cost of care for patients with AVCH was 798.31 \pm 151.23 USD with a minimum of 414.1 USD and a maximum of 1153.74 USD. That of Patients with HCVA was $562.26 \pm 131.7$ USD with a minimum of 236.44 USD and a maximum of 978.81 USD (Table 2).

\section{Discussion}

\subsection{Epidemiological Data}

In our study, the average age of patients was $55.1 \pm 11.8$ years old with extremes of 33 to 78 years and sex-ratio of 1.3. Our results are similar to those of Tépé [5] in 2005, which reported a sex-ratio of 1.3. An average age of 65 years was reported in Tunisia [6] in 1995. In Great Britain, Hayat [7] had reported 73.9 years for whites and 62.5 years for blacks. These different studies in Togo and those in developed countries are due to the fact that the populations of these countries early take in charge of their CVA patients with major risk factors. Male predominance noted in our study was already reported by Balogou in Togo [4], Cowpli et al. in Côte d'Ivoire [8] and Damasceno et al. in Mozambique [9]. We believe that male predominance is due to a higher prevalence of FDRs such as alcohol and tobacco in men as in women, but also to the fact that women are protected by maternity before menopause. On the other hand, a female predominance was noted in Onwuchekwa et al. [10] in Nigeria who reported a sex-ratio of 0.93. According to them, this female predominance is due to bias selection. Traders are more represented with a proportion of $35.2 \%$. Through these results, traders would have been more exposed to the FDRs notably the physical inactivity and settled way of life due to their work. 
Table 2. Cerebrovascular accident overall Costs of hospital admission.

\begin{tabular}{ccc}
\hline & Overallcost (US Dollar) & $\%$ \\
\hline Consulting fees & 546.4 & 1.7 \\
Biological examination frees & 4483.57 & 7.9 \\
Morphological examination frees & $11,235.77$ & 19.8 \\
Drugs fees & $22,050.21$ & 38.8 \\
Admission fees & 7869.68 & 13.8 \\
Transportation and restauration fees & 4021.29 & 7.1 \\
Consumable fees & 3444.35 & 6.0 \\
Services fees & 2777.32 & 4.9 \\
Total & $56,828.59$ & 100.0 \\
\hline
\end{tabular}

\subsection{Clinical Data}

Ischemic CVAs were more frequent in $72.5 \%$ of cases. This ischemic predominance has been observed in several series of this study [11] [12]. We believe that ICVA are predominant because they mostly occur in older patients who are no more represented in our study.

The average duration of stay (ADS) was 18.6 days \pm 7.3 days with extremes of 3 to 36 days. This ADS is similar to that reported by TEPE in Togo [5] who found a ADS of $17.44 \pm 10$ days.

\subsection{Economic Data}

In our study the direct average cost of CVA grant of benefits in our study was $624.49 \pm 197.43$ with a minimum of 236.44 USD and a maximum at 1153.74 USD. Balogou's in Togo [4] and Adoukonou [3] in Benin have reported an average cost of 633.6 USD and 774.9 USD per patient, respectively. On the other hand, Mapoure in Cameroon [13] and Touré et al. in Senegal [14] reported an average cost of 1604.71 USD and 156.85 USD per patient, respectively. In France [15], this cost was 1500 Euros in 30 days with regard to life standard and the luxury in respect of premises. The gap between our results would result from bias selection and socio-economic conditions. The average cost of HCVA was $798.31 \pm 151.23$ USD with a minimum of 414.1 USD and a maximum of 1153.74 USD. In 2005, Tépé in Togo [5] found an average cost at 1029.16 \pm 4010.28 for the HCVA. This difference depending on the type CVA could be explained by the fact that most patients with HCVA are often admitted with serious condition and disorders; and their condition requires intensive care in order to improve and maintain their vital functions. In addition, this neurological morbid table is associated with morbid conditions such as hypertension, diabetes, heart disease, infections, renal insufficiency, which grant of benefits requires specific treatments and a sound medical checkup.

Confronted with the financial issues of the population, the direct average cost of a CVA patient grant of benefits at the medical recovery of the Sylvanus 
Olympio Teaching Hospital is times 8.9 the Guaranteed Minimum Wage (SMIG-GMW) in Togo (70 USD). As a result, it clear that the cost of granting benefits to CVA patients in medical recovery at the Sylvanus Olympio Teaching Hospital surely exceeds the purchasing power of the majority of the Togolese.

The average cost of the supplementary examinations was 172.74 \pm 29.40 USD with a minimum of 105.76 USD and a maximum of 204.12 USD, equal to $27.7 \%$ of the average overall cost. Tépé [5] reported a cost of CFAF 205.57 USD, equal to $27.07 \%$ of the overall average cost.

Pharmaceutical costs on average were $242.31 \pm 75.03$ USD. In Togo, Balogou [4] and Tépé [5] respectively reported close costs of 224.47 USD and 223.18 USD. The cost of stay depends on the type of accommodation and duration of stay. These costs are invoiced as follows: at recovery $5 \mathrm{USD} /$ day in the first week, 3.5 USD/day in the second week, 2.4 USD/day from the third week, CFAF 10 $\mathrm{UD} /$ day in the private cabin and $2.4 \mathrm{USD} /$ common room. In our study, the majority of CVA patients in convalescent phase stayed in cabins. Hospital costs on averaged were $86.48 \pm 41.19$ USD with a minimum of 7.5 USD and a maximum of 171.8 USD. In Benin, Adoukonou [3] reported an average cost of 101.92 USD of hospitalization.

\section{Conclusion}

CVAs are nowadays a major public health problem due to its morbidity and mortality and its economic impact. This present study shows that the cost of hospitalization of CVA patients is too high for Togolese, hence there is the need for a primary prevention of the risk factors of this pathology and the effective implementation of an universal health coverage.

\section{References}

[1] WHO Task Force on Stoke and Other Cerebrovascular Disorders (1989) Recommendations on Stoke Prevention, Diagnostic and Therapy. Stroke, 20, 1407-1431.

[2] Ovbiagele, B., and Nguyen-Huynh, M.N. (2011) Stroke Epidemiology: Advancing Our Understanding of Disease Mechanism and Therapy. Neurotherapeutics, 8, 319-329. https://doi.org/10.1007/s13311-011-0053-1

[3] (2013) Coût hospitalier direct des Accidents Vasculaires Cérébraux à Parakou au Nord du Bénin. The Pan African Medical Journal, 16, 121.

[4] Balogou, A.A.K., Tossa, K.R., Kowu, A., Belo, M., and Grunitzky, K.E.(2004) Prix de revient d'une hospitalisation dans le service de neurologie du CHU de Lomé (Togo). Cahiers d'études et de recherches francophones/santé, 14, 109-114.

[5] Tépé, E.M.S. (2005) Le coût des AVC dans les services de neurologie aux CHU de Lomé. Thèse de doctorat de Médecine, Faculté mixte de médecine et de pharmacie, Université de Lomé, Togo.

[6] Chell, S. and Chelli, M. (1995) Approche épidémiologique des AVC. Maghreb Médical, 10, 23-33.

[7] Hajat, C., Dundas, R., Stewart, J.A., Lawrence, E., Rudd, A.G., Howard, R. and Wolfe, C.D.A. (2001) Cerebrovascular Risk Factors and Stroke Subtypes: Differences between Ethnic Groups. Stroke, 32, 37-42. 
https://doi.org/10.1161/01.STR.32.1.37

[8] Cowppli-Boni, P., Souman-Douayoua, T., Datie, A.M., Assi, B., Aka-Diarra, E., Boa Yapo, F. and Kouassi, E.B. (2004) Epidémiologie des patients hospitalisés en neurologie: expérience du centre hospitalier universitaire de Cocody à Abidjan (Côte d'Ivoire). African Journal of Neurological Sciences, 23, 16-23.

[9] Damasceno. A., Gomes. J., Azevedo, A., et al. (2010) An Epidemiological Study of Stroke Hospitalizations in Maputo, Mozambique: A High Burden of Disease in a Resource Poor Country. Stroke, 41, 2463-2469. https://doi.org/10.1161/STROKEAHA.110.594275

[10] Onwuchekwa, A.C., Onwuchekwa, R.C. and Asekomeh, E.G. (2009) Stroke in Young Nigeria Adults. Journal of Vascular Nursing, 27, 98-102. https://doi.org/10.1016/j.jvn.2009.08.001

[11] Yukihiro, Y., Satoshi, H., Rikuzo, T., Jun, G., Manabu, W., Yasushi O., Kiyonobu, Y., Seturo, I. and Yasuhiro, H. (2005) Hospital Cost of Ischemic Stroke and Intracerebral Heamorrhage in Japanese Stroke Centers. Heath Policy, 73, 202-211. https://doi.org/10.1016/j.healthpol.2004.11.016

[12] Smada, D., Cabre, P., May, F., Fanon, J.L., Rene-Corail, P., Charpentier, J.C., Fournrie, P., Saint-Vil, M., Ketterie, J. and ERMANCIA Study Group (2001) Epidemiology of Stroke in Martinique, French West Indies: Part I: Methodology, Incidence and 30-Day Case Fatality Rate. Stroke, 32, 2741-2747. https://doi.org/10.1161/hs1201.099385

[13] Mapoure, Y.N., Kuate. C., Bibaya Anaba Kouna, P.E., Luma, H.N., Mouelle, A.S. and Njamnshi AK. (2014) Coût des accidents vasculaires cérébraux à Douala. Human Health and Disease, 15, 1-6.

[14] Touré, K., Ndiaye, N.M., Diouf, F., Sène. F., Ndiaye, M., Diallo. K., Ndao. A.K. et al. (2005) Evaluation du coût de prise en charge des accidents vasculaires cérébraux à Dakar-Sénégal. Medecine Tropicale, 65, 458-464.

[15] Spieler, J.F. and Amarenco, P. (2004) Aspects sociaux économiques de la prise en charge de l'attaque cérébrale. Revue Neurologique, 160, 1023-1028.

https://doi.org/10.1016/S0035-3787(04)71139-X 